\title{
ORAL CLONIDENE IN CHILDREN: EFFICACY AS PREMEDICANT AND EFFECT ON POSTOPERATIVE RECOVERY. (COMPARISON OF TWO DIFFERENT DOSES $3 \mu \mathrm{g} / \mathrm{kg}$ AND $4 \mu \mathrm{g} / \mathrm{kg}$ )
}

Devyani Desai, V. N. Swadia, Alok Sahoo

1. Associate Professor, Department of Anaesthesia, Medical College, Vadodara.

2. Professor \& Head, Department of Anaesthesia, Medical College, Vadodara.

3. Ex Student, Department of Anaesthesia, Medical College, Orissa.

\section{CORRESPONDING AUTHOR}

Dr. Devyani Desai,

22, Soham Bunglows- 1,

B/H: Palm View apt.

Vasna road,Vadodara, Gujarat.

E-mail: devyani.dr@gmail.com

Ph: 00919909983168

ABSTRACT: BACKGROUND: This study was conducted to see the efficacy of two different doses of oral clonidine as a premedication in pediatric patients. MATERIAL AND METHOD: In a prospective randomized study of 60 cases of 4-12 year old children receiving oral clonidine either $3 \mu \mathrm{g} / \mathrm{kg}$ (group $\mathrm{C}_{3}$ ) or $4 \mu \mathrm{g} / \mathrm{kg}$ (group $\mathrm{C}_{4}$ ) as a premedication 90 minutes prior to surgeries. Preoperatively, the level of sedation, response to parental separation, mask acceptance, intravenous cannulation and response to intubation as well as hemodynamic were noted. Postoperative recovery was assessed using Alderate recovery room score. RESULTS: Clonidine $4 \mu \mathrm{g} / \mathrm{kg}$ group had higher sedation score compared to clonidine $3 \mu \mathrm{g} / \mathrm{kg}$. At 90 minutes, almost $90 \%$ children in $\mathrm{C}_{4}$ group were asleep but arousable on calling and in $\mathrm{C}_{3}$ group $33 \%$ were asleep, $60 \%$ were drowsy and rest $7 \%$ children were calm. Parental separation and mask acceptance scores were also higher with clonidine $4 \mu \mathrm{g} / \mathrm{kg}$ group. The response to intubation was better attenuated in clonidine $4 \mu \mathrm{g} / \mathrm{kg}$ group. There was no respiratory depression or oxygen desaturation at any point of time in our study perioperatively and no delay in postoperative recovery as well as no significant difference in the incidence of post operative nausea and vomiting in both the groups. CONCLUSION: Oral clonidine $4 \mu \mathrm{g} / \mathrm{kg}$ provided better sedation than clonidine $3 \mu \mathrm{g} / \mathrm{kg}$ without prolonging the postoperative recovery.

KEYWORDS: Oral clonidine, Premedication, Pediatric

INTRODUCTION: Planning and carrying out a smooth transition from child's awake normal state to condition of surgical anaesthesia is one of anesthesiologist's greatest challenges. The anesthesiologist should always consider the child's emotional needs and create an environment that will minimize or abolish fear and distress. Therefore, the anesthetic practice in this age group demands a continuous search for an ideal premedicant that can be administered by convenient route to the pediatric patient.

Clonidine, the $\alpha 2$ agonist has the property of good anxiolysis and sedation without causing respiratory depression. It has antisialogogue and analgesic action. It also prevents the hemodynamic response to intubation, decreases the doses and minimum alveolar concentration (MAC) value of anesthetic agent and prevents post operative nausea and vomiting. $(1,2,3,4,5,6,7,8)$ Along with its rapid and smooth postoperative recovery profile and low cost makes it a good premedication of choice. $(3,4,5,6$, , Considering all, we planned the study to compare two different 
doses of clonidine $3 \mu \mathrm{g} / \mathrm{kg}$ and $4 \mu \mathrm{g} / \mathrm{kg}$, to identify its efficacy and it's other advantage and disadvantage.

AIMS OF STUDY:

We compared following parameters.

(1) Level of sedation.

(2) Anxiolysis e.g. response to parental separation, intravenous cannulation, face mask application.

(3) Hemodynamic response to clonidine e.g. pulse rate, blood pressure changes in preoperative period and during laryngoscopy and intubation.

(4) Changes in Respiratory rate and Oxygen saturation

(5) Antisialogogue effect

(6) Postoperative recovery

(8) Postoperative nausea and vomiting.

MATERIALS \& METOD: This was a prospective randomized, single blind, comparative clinical study comprised of 60 pediatric patients of comparable weight \& either sex, aged 4 to 12 years of ASA grade I and II undergoing elective surgeries like Otolaryngeal, Plastic, Orthopedic, General and Ophthalmic surgeries.

The following patients were excluded from study.

1. History of recent URTI.

2. Any congenital anomaly of heart, kidney and gastro intestinal tract.

3. If they are judged to have very difficult intravenous access.

4. Known to have any drug allergy.

Thorough preoperative assessment was done. Specific Consideration included.

1. Vital parameters

2. Haemogram, Random blood sugar

3. Urine Albumin and Sugar

4. Airway assessment.

All parents were explained details about the procedure. A written and informed consent was taken. All patients were kept nil by mouth for 6 hours for solid and non clear liquid and 2-3 hours for clear fluid and they were divided randomly into two groups, 30 patients in each group.

\section{Group $\mathrm{C}_{3}$ - Oral Clonidine $3 \mu \mathrm{g} / \mathrm{kg}+\mathrm{inj}$. Atropine $0.03 \mathrm{mg} / \mathrm{kg}$ Group $\mathrm{C}_{4--}$ Oral Clonidine $4 \mu \mathrm{g} / \mathrm{kg}+\mathrm{inj}$. Atropine $0.03 \mathrm{mg} / \mathrm{kg}$}

The clonidine tablet (Arkamine) $100 \mu \mathrm{g}$ was dissolved in $5 \mathrm{ml}$ of $25 \%$ dextrose to make it more palatable and appropriate dose according to weight. Then Injection Atropine taken at a dose $0.03 \mu \mathrm{g} / \mathrm{kg}$ into same syringe and given to child to be taken orally 90 minute before surgery in the preparation room. The children were kept in bed along with parents.

The children were monitored at 0 , (basal) 30, 40, 50, 60, 70, 80 and 90 minutes with following parameters. 
- $\quad$ Pulse Rate

- $\quad$ Systolic Blood Pressure

- Respiratory rate

- $\quad \mathrm{SPO}_{2}$

- $\quad$ Level of Sedation with following score (9)

0- $\quad$ Agitated, crying, clinging to parents.

1- $\quad$ Alert, awake but not cling to parent

2- $\quad$ calm, sitting or lying comfortable with eyes spontaneously opening

3- drowsy, lying comfortably with eyes closed but responds to minor stimuli

4- asleep, eyes closed and not responds to minor stimuli.

- Response to parental separation as (10)

0 - poor (anxious, combative).

1- $\quad$ good (anxious but easily reassured)

2- excellent (calm, drowsy)

Then the child was taken to operation theater. The response to intra venous cannulation with appropriate cannula (1-crying, 2-calm) and response to facemask application noted with 5 point rating scale. (1- agitated, 2-alert, initially refuse then accept mask, 3-calm and accept mask, 4Drowsy, accept mask, 5-Asleep, accept mask) (11)

After preoxygenation with $100 \%$ oxygen for 3minutes, all patients were induced with Injection Pentothal sodium (4-7 mg/kg) intravenously till loss of eye lash reflex. Then injection Succinylcholine $2 \mathrm{mg} / \mathrm{kg}$ was given intravenously. Oral endotracheal intubation was done with appropriate sized cuffed or plain tube. During Intubation the following parameters were monitored to indentify the response to intubation at 1, 3 and 5 minutes.

(a) Pulse rate

(b) Systolic blood pressure

(c) Secretion as 0 - None

1 - Mild

2 - Moderate

3 - Copious

Anesthesia was maintained with $\mathrm{O}_{2}$ and $\mathrm{N}_{2} \mathrm{O}$ (50:50\%) with Isoflurane and Injection Vecuronium Bromide. At the end of surgery, residual motor block was antagonized by Injection Neostigmine $0.05 \mathrm{mg} / \mathrm{kg}$ and Injection Glycopyrrolate $0.01 \mathrm{mg} / \mathrm{kg}$ intravenously. Once response to verbal command, intact airway protective reflex and other extubation criteria fulfilled, children were extubated and shifted to recovery room. All children were monitored for 6 hours post operatively in the recovery room. Alderate recovery room score were recorded at 10 minute interval for 30 minutes, then every 30 minutes for 2 hours and then every hourly for 6 hours. Patients must score greater than 9 for safe discharge from the recovery room. Children were given paracetamol syrup $10 \mathrm{mg} / \mathrm{kg}$ if they complained for pain at the surgical site. The incidence and time of occurrence of vomiting were recorded within 6 hours of operation. Any other side effect like hypotension systolic blood pressure $(<70 \mathrm{~mm}$ of $\mathrm{Hg}$ ) rebound hypertension (systolic blood pressure $>140 \mathrm{~mm}$ of $\mathrm{Hg}$ ), bradycardia (Heart rate $<60$ beats/minute) and hypoxia (SPO2 $<90 \%$ ) noted during post 
operative period. The demographic variables and vitals were compared using Student ' $t$ ' test. The sedation and anxiolysis scores were compared using the Mann- Whiteny test and ChiSquare test. A P value $\leq 0.05$ considered as significant.

OBSERVATION \& RESULTS: As shown in table 1, the two groups were comparable in respect to age, sex, height, weight and ASA grading. However, unintentional male predominance found in both groups.

Table 2 suggests that the baseline sedation score was comparable between two groups. In both groups there was increase in sedation score as time elapsed. The rise in mean sedation score was statistically significant after 30 minutes where the score was higher in $\mathrm{C}_{4}$ group compared to $\mathrm{C}_{3}$ group.

The graph 1 shows that $76.67 \%$ in group $C_{3}$ and in $94 \%$ children in group $C_{4}$ were separated easily. The graph 2 shows that less children were crying on intravenous cannulation in group $\mathrm{C}_{4}\left(66.6 \%\right.$ in group $\mathrm{C}_{3} \mathrm{v} / \mathrm{s} 40 \%$ in group $\left.\mathrm{C}_{4}\right)$.

Responses to face mask application inside Operation Theater were as shown in graph 3. In $\mathrm{C}_{3}$ group $53.26 \%$ children were calm and accepted mask easily. $10 \%$ children refused mask \& $36.6 \%$ child accepted mask after persuasion. But in Group $\mathrm{C}_{4} 93.2 \%$ children had excellent mask acceptance and only $6.6 \%$ children accepted mask after persuasion.

As shown in graph 4 , the base line pulse rate $(122.00 \pm 7.97)$ in group $C_{3}$ and $(122.66$ \pm 4.37 ) in group $C_{4}$ was comparable. There was significant difference in pulse rate at 60 and 70 minutes between two groups and the difference became highly significant at 80 and 90 minutes.

As shown in graph 5, the baseline systolic blood pressure between two groups $\left(114.33 \pm 3.28\right.$ in $\left.\mathrm{C}_{3}\right)$ and $\left(115.06 \pm 3.81\right.$ in $\mathrm{C}_{4}$ ) was comparable. The systolic blood pressure decreased in both groups but there was significant decrease in systolic blood pressure in Group $\mathrm{C}_{4}$ at 40 minutes and the decrease was highly significant after 50 minutes in $\mathrm{C}_{4}$ as compared to $\mathrm{C}_{3}$ group.

The table $3 \mathrm{~A}$ and $3 \mathrm{~B}$ show the pulse rate and blood pressure between two groups during intubation which were compared at 1, 3, 5 minutes in both groups. There was rise in both from the 90 minutes value in both groups but the rise was highly significant in $\mathrm{C}_{3}$ group compared to $\mathrm{C}_{4}$ group at all intervals. $85 \%$ in group $\mathrm{C}_{4}$ and $83.3 \%$ in group $\mathrm{C}_{3}$ had no secretion and $16.6 \%$ in group $\mathrm{C}_{3} \& 15 \%$ in group $\mathrm{C}_{4}$ showed mild secretion.

During postoperative period there was no respiratory depression and oxygen desaturation seen in both the groups. But children in group $\mathrm{C}_{4}$ were more sedated compared to group $\mathrm{C}_{3}$. By 120 minutes, all children in group $\mathrm{C}_{3}$ were fully awake and by 240 minutes, all children in group $\mathrm{C}_{4}$ were fully awake. At no point of time recovery score was below 7 .

9.9\% children in $C_{3}$ group and $6.6 \%$ children in $C_{4}$ group had postoperative nausea and vomiting (PONV). Comparing both groups, incidences of PONV were statistically insignificant.

DISCUSSION; The anaesthetic management in pediatric age group is a challenge, as they are aware of strange hospital environment and parental separation in contrast to adult who are usually concerned about the prospect of surgery and health; children were principally worried about pain and separation from parents so sedation and anxiolysis are the essential components of pediatric anaesthesia.

We prefer oral route for administration of drugs in our study because it avoids fear of needle prick and is most convenient route for administration. We made drug more palatable and sweet by administering it with $25 \%$ dextrose. The clonidine has $95 \%$ oral bioavailability 
via oral route and absorption is complete $(1,2)$. In our study we added Atropine simultaneously at a dose $0.03 \mathrm{mg} / \mathrm{kg}$ to add the antisialogogue effect of clonidine and also Atropine can act as an effective antidote for bradycardia and hypotension which reported by Mikawa et al with the use of clonidine $5 \mu \mathrm{g} / \mathrm{kg}{ }^{(4)}$. Also, it has good oral bioavailability.

Clonidine orally used with dose schedule from $1-5 \mu \mathrm{g} / \mathrm{kg}$ but appropriate dosing is still under investigation. Clonidine $2 \mu \mathrm{g} / \mathrm{kg}$ used by Mikawa et al \& Malde et al causing no benefit $(3,9)$. Clonidine $3 \mu \mathrm{g} / \mathrm{kg}$ used by Ramesh et al showed sedation effect comparable to diazepam (10). Clonidine $4 \mu \mathrm{g} / \mathrm{kg}$ used by Mikawa et al, Remier et al, Batra et al and Malde et al $(3,5,8,10,13,14)$. They found that clonidine $4 \mu \mathrm{g} / \mathrm{kg}$ had better sedation, anxiolysis and attenuation of haemodynamic response than diazepam. So we tried the dosing schedule $3 \mu \mathrm{g} / \mathrm{kg} \& 4 \mu \mathrm{g} / \mathrm{kg}$ for getting maximum benefit without adverse effect.

In both the groups there was a significant rise in sedation score from the baseline value. The peak sedation was seen at 90 minutes where the sedation score in $\mathrm{C}_{3}$ group was 3.26 and $\mathrm{C}_{4}$ group was 3.90 i.e. at 90 minute almost $90 \%$ children in $\mathrm{C}_{4}$ group were asleep but arousable on calling and in $\mathrm{C}_{3}$ group 33\% were asleep, $60 \%$ were drowsy and rest $7 \%$ children were calm. Our results were comparable to Y K Batra et al, Ramesh et al, Mikawa et al, Fazi et al and Malde et al $(3,10,12,14,15,16,17)$.

The sedation in clonidine is mainly due to stimulation of $\alpha_{2}$ receptor in the locus cerulus in the brainstem. Activation of $\alpha 2$ receptor suppresses the spontaneous firing rate of locus coerulus. This results in an increasing activity of inhibitory interneuron's such as GABAergic pathways to produce CNS depression. (12). At the point of maximum anxiolysis i.e. when children were sleepy, drowsy or calm, they were shifted to the operation theater which was 90 minutes after giving premedication in our study. Clonidine $4 \mu \mathrm{g} / \mathrm{kg}$ is more effective for preinduction sedation than oral diazepam $0.4 \mathrm{mg} / \mathrm{kg}$ if it is administered at least 90 minutes before induction (12).

The response to parental separation was graded as excellent, good and crying. As shown in graph 3 , in group $\mathrm{C}_{3} 76.6 \%$ children were easily separable and $23 \%$ were crying but in group $\mathrm{C}_{4}$ $94 \%$ children were easily separated, only $6 \%$ were anxious of parental separation. Mikawa et al reported clonidine $4 \mu \mathrm{g} / \mathrm{kg}$ has better parental separation than clonidine $2 \mu \mathrm{g} / \mathrm{kg}$ or oral diazepam (3). Malde et al showed there was no difference between two doses of clonidine $4 \mu \mathrm{g} / \mathrm{kg}$ or $2 \mu \mathrm{g} / \mathrm{kg}$ but in our study group $\mathrm{C}_{4}$ had significantly better parental separation than group $C_{3}(10)$. Mithani et al 1984 in a study of effect of $\alpha_{2}$ agonist and antagonist in maze exploration model of fear motivated behavior study showed that clonidine also causes anxiolysis independent of sedation.

Response to intravenous cannulation was graded as calm or crying. As shown in graph 4, $66.6 \%$ children in group $\mathrm{C}_{3}$ and $40 \%$ children in group $\mathrm{C}_{4}$ were crying during intravenous cannulation. Our results coincide with Malde et al (10). Higher percentage of children responded to intravenous cannulation compared to Mikawa et al in 1993 because they have used $\mathrm{O}_{2}$ and $\mathrm{N}_{2} \mathrm{O}$ inhalation via face mask during intravenous cannulation to decrease pain of needle prick. In a study by American dental society of anesthesiology 2006, oral clonidine pretreatment prior to intravenous cannulation in adult showed that clonidine increases the acceptance of intravenous cannulation by decreasing discomfort and pain and clonidine also increase cutaneous blood flow enable easier intravenous access ${ }^{(18)}$. As shown in graph 5 , in group $\mathrm{C}_{4}$, more number of children were calm and accepted mask easily than in group $\mathrm{C}_{3}$ and similar to the study done by Mikawa et al and Malde et al ${ }^{3,10)}$. 
Comparing both the groups, the decrease in pulse rate was statistically insignificant. Comparing base line value in each group, there was highly significant decrease in pulse rate at all time interval but we did not encounter a single case of troublesome bradycardia. Similarly, Ramesh et al and Mikawa et al also showed significant decrease in pulse rate with clonidine but in no case bradycardia occurred $(8,12)$.

Following premedication in both the groups, there was fall in systolic blood pressure significantly. The decrease in systolic blood pressure started from 30 minutes onwards. The fall in systolic blood pressure was statistically highly significant when compared with basal level in both the groups. Our results were similar to Mikawa et al , Fazi et al and Malde et al $(3,10,15)$. The peak effect was seen at 90 minutes corresponded to peak plasma concentration of clonidine. The cardiac action of clonidine was due to imidazoline specific receptor in nucleus reticularis lateralis of brain stem and thus decreases in central sympathetic output. (Teberica et al 1991). Clonidine also acts by decreasing sympathetic tone and lowers set point around which arterial blood pressure regulated (Badoen et al 1983) (1,2). Based on observation, Rozen 1988 concluded that, a preoperative pharmacological sympathectomy with clonidine in oral doses $\leq 5 \mu \mathrm{g} / \mathrm{kg}$ appears to be safe and useful stabilizer of both heart rate and blood pressure as well as myocardial performance ${ }^{3,8)}$.

As shown in table $3 \mathrm{~A}$ and $3 \mathrm{~B}$, there was rise in pulse rate and blood pressure from the 90 minutes value in both groups but it was highly significant in $\mathrm{C}_{3}$ group compared to $\mathrm{C}_{4}$ group at all intervals. The stress response was maximally attenuated in $\mathrm{C}_{4}$ group. Our results tally with study by Mikawa et al, Ramesh et al , Malde et al and Raval DL et al (3,8,10,12,19). Clonidine may successfully attenuate hemodynamic changes following intubation in children and may be suitable than opioids because of less respiratory depressive effect ${ }^{(8)}$. The heart rate decreased after 90 minutes of clonidine administration and the difference between two groups was maintained before induction, after induction and after intubation. So it appears that the decreased in tachycardic response to intubation with clonidine was due to generalized reduction in heart rate even prior to induction. Mikawa et al also demonstrated that clonidine inhibits central sympathetic flow with resultant suppression of catecholamines (8).

There was no significant change in respiratory rate and $\mathrm{Spo}_{2}$ in either group at any interval. The small decrease in respiratory rate from basal level was due to reduction of anxiety and due to sedation. Mikawa et al, Ramesh et al and Fazi et al also observed the same. $(3,12,15,16,17)$

We observed for any secretion in oral cavity during intubation and only $16.6 \%$ children in group $C_{3}$ and $15 \%$ children in group $C_{4}$ had mild oral secretion. Clonidine decreases salivary secretion by inhibiting Acetylcholine release (Watkins et al 1980) and as we had also taken oral Atropine simultaneously which added to antisialogogue effect (10).

After tracheal extubation all children transferred to recovery room. A modified Alderate score of at least 9 out of 10 indicates readiness for discharge. We observe all children for 6 hours postoperatively. In our study postanaesthtic recovery was not delayed or not affected by clonidine. Our results were comparable with Mikawa et al, Ramesh et al, Batra et al and Malde et al $(3,10,12,14)$. In study of psychomotor function and sedation following clonidine premedication by Batra et al showed that clonidine $4 \mathrm{mcg} / \mathrm{kg}$ produce good sedation and least effect on psychomotor function (14). Nausea and vomiting in post operative period causes significant distress to any patient and delay the discharge. In our study only $9.9 \%$ children in group $\mathrm{C}_{3}$ and $6.6 \%$ children in group $\mathrm{C}_{4}$ had nausea and vomiting. There was no statistically significant difference between two groups. Mikawa et al and Malde et al also reported the same in their study $(3,10)$. 
Thus, clonidine $3 \mu \mathrm{g} / \mathrm{kg}$ and $4 \mu \mathrm{g} / \mathrm{kg}$ with Atropine $0.03 \mathrm{mg} / \mathrm{kg}$ can be used as an oral premedication before 90 minute of induction of general anaesthesia in children to produce good sedation, anxiolysis, no respiratory depression and attenuation of hemodynamic response to intubation without causing any delay in the post operative recovery and with less incidence of PONV but clonidine $4 \mu \mathrm{g} / \mathrm{kg}$ gives better results than $3 \mu \mathrm{g} / \mathrm{kg}$.

\section{BIBILOGRAPHY:}

1. 1. Hayashi Y, Maze M. Alpha2 adrenoreceptors agonists and anaesthesia. Br J Anaesth 1993;71:108-18.

2. Maze M, Tranquilli W. Alpha -2 agonists. Defining the role in clinical anesthesia. Anesthesiology 1989;74:581-605.

3. Mikawa K, Maekawa N, Nishina K, Takao Y, Yaku H, Obara H. Efficacy of oral clonidine premedication in children. Anesthesiology $1993 ; 79(5): 926-31$.

4. 4. Nishina K, Mikawa K, Shiga M, Obara H. Clonidine in paediatric anaesthesia. Paediatr Anaesth 1999; 9: 187-202.

5. K Mikawa,K Nishina,N Maekawa, and H Obara. Oral clonidine premedication reduces postoperative pain in children. Anaes Analg 1996;40(6):746-51.

6. Nishina K, Mikawa K, Shiga M, et al. Oral clonidine premedication reduces minimum alveolar concentration of sevoflurane for tracheal intubation in children. Anesthesiology 1997; 87: 1324-7.

7. 7. Nishina K, Mikawa K, Maekawa N, et al. Clonidine decreases the dose of thiamylal required to induce anesthesia in children. Anesth Analg 1994; 79: 766-8.

8. K Mikawa,K Nishina,N Maekawa,Y Takao,M Asano and H Obara Attenuation of the catecholamine response to tracheal intubation with oral Clonidine in children. Can J Anesth 1995; 42:869-874.

9. C. O. McMillan, I.A.Spahr-Schofer, N. Sikich, E.Hartley, J. Lerman. Premedication of children with oral midazolam. Can J Anaesth 1992;39:545-50.

10. Anila Malde, Radha Pagedar, Sheetal Jagtap. Oral clonidine in children:efficacy as premedicant and post operative analgesic as compared to diazepam.Ind J Anesth 2006;50(1):27-31.

11. Nicole Almenrader, Maurizio Passariello, Bruno Coccetti, Roberta Haiberger, Paolo Pietropaoli. Premedication in children: A comparison of oral midazolam and oral clonidine. Pediatric Anesthesia 2007; 17: 1143-49.

12. Ramesh VJ, Bharadwaj N, Batra YK. Comparative study of oral clonidine and diazepam as premedicants in children. Int J clin Pharmacol Ther 1997 ;35(5):218-21.

13. Reimer EJ, Dunn GS, Montgomery CJ, Sanderson PM.The effectiveness of clonidine as an analgesic in paediatric adeno-tonsillectomy. Can J Anesth 1998 ;45(12):1162-67.

14. 14. Batra YK, Jatti $\mathrm{K}$, Bharadwaj N, Malhotra S.Comparison of psychomotor functions and sedation following pre medication with oral diazepam and clonidine in children. Int J clin Pharmacol Ther 1998 ;36(6):336-39.

15. Fazi L, Jantzen EC, Rose JB, Kurth CD,Watcha MF.A comparison of oral clonidine and oral midazolam as peranesthetic medication in the pediatric tonsillectomy patient. Anesth Analg 2001 ;92(1):56-61.

16. Bergendahl HT, Lonnqvist PA,Eksborg S, Ruthstorm E, Oddby E. Clonidine v/s midazolam as premedication in children undergoing adeno-tonsillectomy. Acta Anesthiol Scand 2004 ;48(10):1292-300.

17. Bergendahl HT, Lonnqvist PA, Eksborg S, Staffan C. Clonidine : an alternative to benzodiazepines for premedication in children. Current opinion in anesthesiology 2005;18(6):608-13. 
18. David Hall, Ehsan Rezwan, Dimitris N, Walters.Oral clonidine pre treatment prior to venous cannulation.Anaes Prog 2006;53:34-42.

19. Raval DL, Mehta MK. Oral clonidine pre medication for attenuation of hemodynamic response to laryngoscopy and intubation. Ind J Anaesth 2002; 46(2):124-129.

Table 1. DEMOGRAPHIC DATA

\begin{tabular}{|l|c|c|c|}
\hline & Group $_{\mathbf{3}}$ & ${\text { Group } \mathbf{C}_{\mathbf{4}}}$ & P. Value \\
\hline AGE (YEAR) & $8 \pm 2.43$ & $8.41 \pm 3.42$ & $\mathrm{P}>0.05$ \\
\hline WEIGHT(KG) & $20.033 \pm 5.63$ & $20.36 \pm 4.86$ & $\mathrm{P}>0.05$ \\
\hline $\begin{array}{l}\text { SEX } \\
\text { MALE/ FEMALE }\end{array}$ & $17 / 13$ & $20 / 10$ & \\
\hline ASA GRADING & & & $\mathrm{P}>0.05$ \\
\hline ASAI & $20(66.66 \%)$ & $18(60 \%)$ & $\mathrm{P}>0.05$ \\
\hline ASA II & $10(33.33 \%)$ & $12(40 \%)$ & $\mathrm{P}>0.05$ \\
\hline $\begin{array}{l}\text { DURATION OF } \\
\text { SURGERY(MIN) }\end{array}$ & $129.137 \pm 15.64$ & $128.33 \pm 17.38$ & \\
\hline
\end{tabular}

TABLE 2 - SEDATION SCORE

\begin{tabular}{|l|c|c|c|c|c|c|c|c|c|c|c|c|c|}
\hline & \multicolumn{9}{|c|}{ C $_{\mathbf{3}}$ GROUP } & \multicolumn{7}{c|}{ CRROUP $_{\mathbf{4}}$ GROAN } & \\
\hline \multicolumn{1}{|c|}{ TIME } & $\mathbf{0}$ & $\mathbf{1}$ & $\mathbf{2}$ & $\mathbf{3}$ & $\mathbf{4}$ & MEAN & $\mathbf{0}$ & $\mathbf{1}$ & $\mathbf{2}$ & $\mathbf{3}$ & $\mathbf{4}$ & MEAN & P.VALUE \\
\hline 0 & 26 & 4 & 0 & 0 & 0 & 0.133 & 25 & 5 & 0 & 0 & 0 & 0.166 & $\mathrm{P}>0.05$ \\
\hline 30 & 0 & 25 & 5 & 0 & 0 & 1.16 & 0 & 20 & 10 & 0 & 0 & 1.33 & $\mathrm{P}<0.05$ \\
\hline 40 & 0 & 10 & 17 & 3 & 0 & 1.93 & 0 & 2 & 20 & 8 & 0 & 2.2 & $\mathrm{P}<0.05$ \\
\hline 50 & 0 & 0 & 24 & 4 & 2 & 2.26 & 0 & 0 & 5 & 18 & 7 & 3.06 & $\mathrm{P}<0.001$ \\
\hline 60 & 0 & 0 & 14 & 13 & 3 & 2.63 & 0 & 0 & 2 & 11 & 17 & 3.5 & $\mathrm{P}<0.001$ \\
\hline 70 & 0 & 0 & 9 & 14 & 7 & 2.93 & 0 & 0 & 1 & 9 & 20 & 3.63 & $\mathrm{P}<0.001$ \\
\hline 80 & 0 & 0 & 5 & 16 & 9 & 3.13 & 0 & 0 & 0 & 5 & 25 & 3.83 & $\mathrm{P}<0.001$ \\
\hline 90 & 0 & 0 & 2 & 18 & 10 & 3.26 & 0 & 0 & 0 & 3 & 27 & 3.9 & $\mathrm{P}<0.001$ \\
\hline
\end{tabular}


GRAPH 1: RESPONSE TO PARENTAL SEPARATION

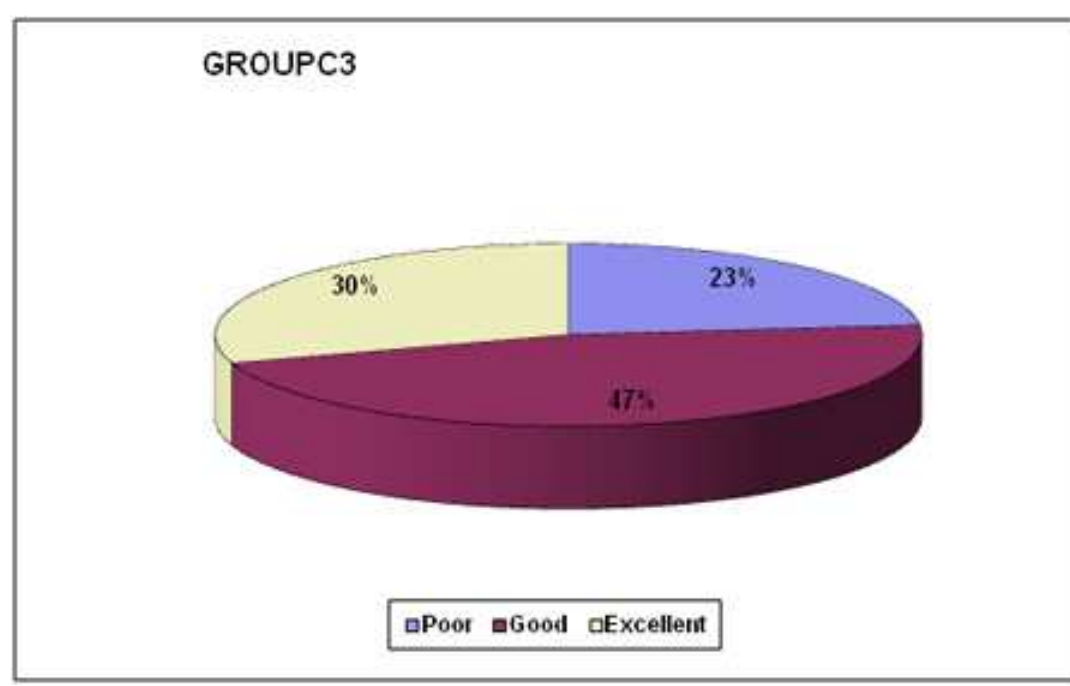

GROUP C4

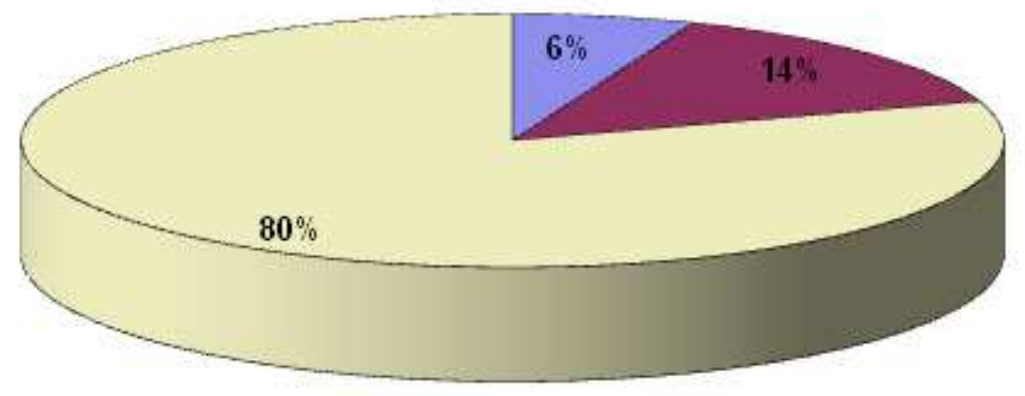

口Poor agood aExcellent 


\section{GRAPH 2: RESPONSE TO INTRA VENOUS CANNULATION}

\section{GROUPC3}

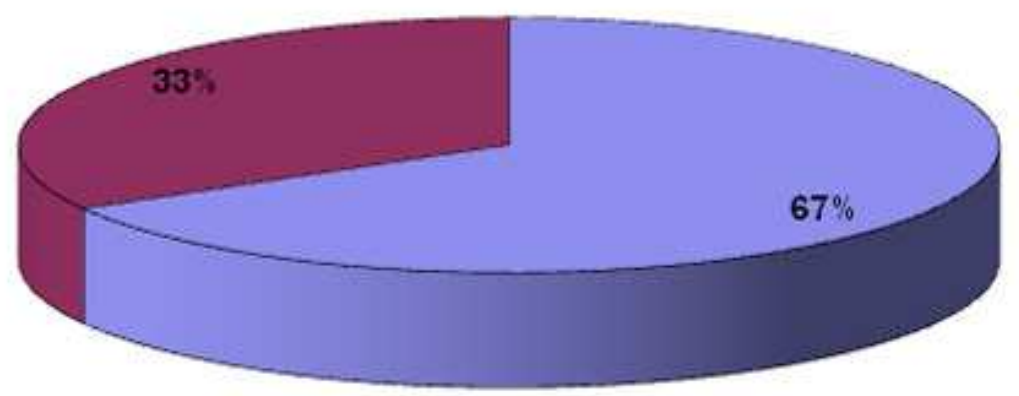

口Crying aCalm

\section{GROUPC4}

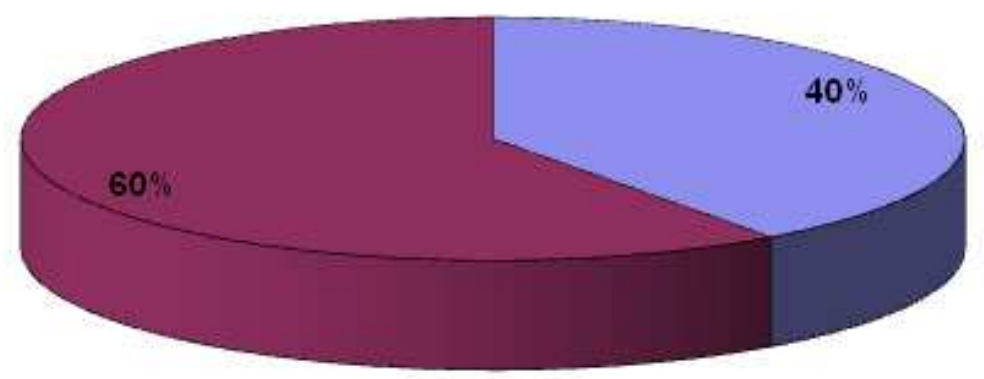

口Crying aCalm 
GRAPH 3: RESPONSE TO FACE MASK APPLICATION

\section{GROUP C3}
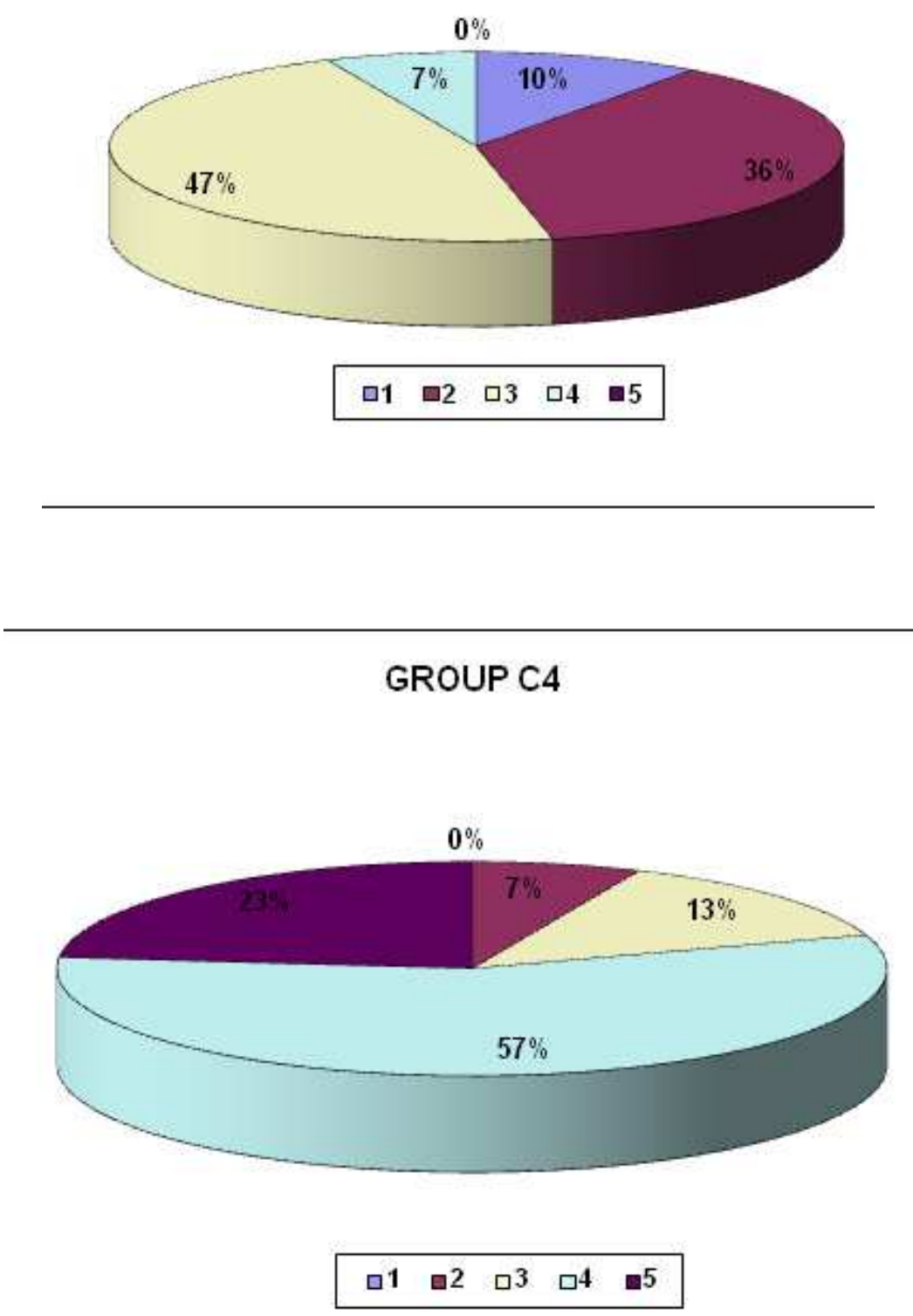


\section{ORIGINAL ARTICLE}

\section{GRAPH 4}

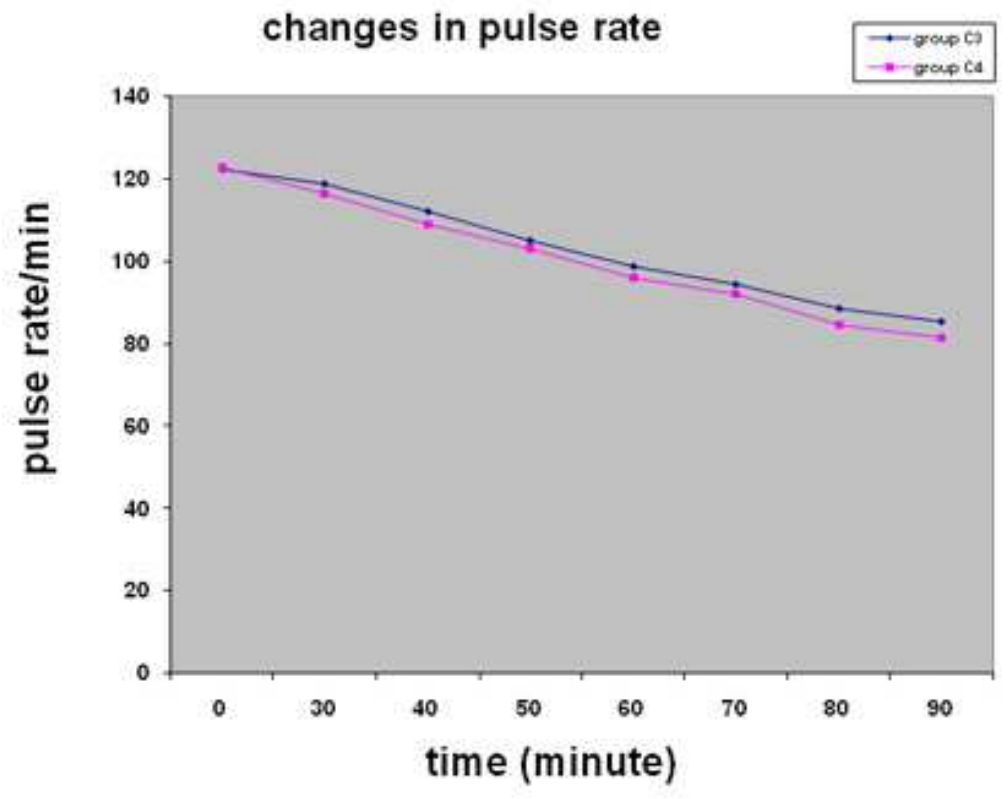

\section{GRAPH 5}

changes in systolic blood pressure
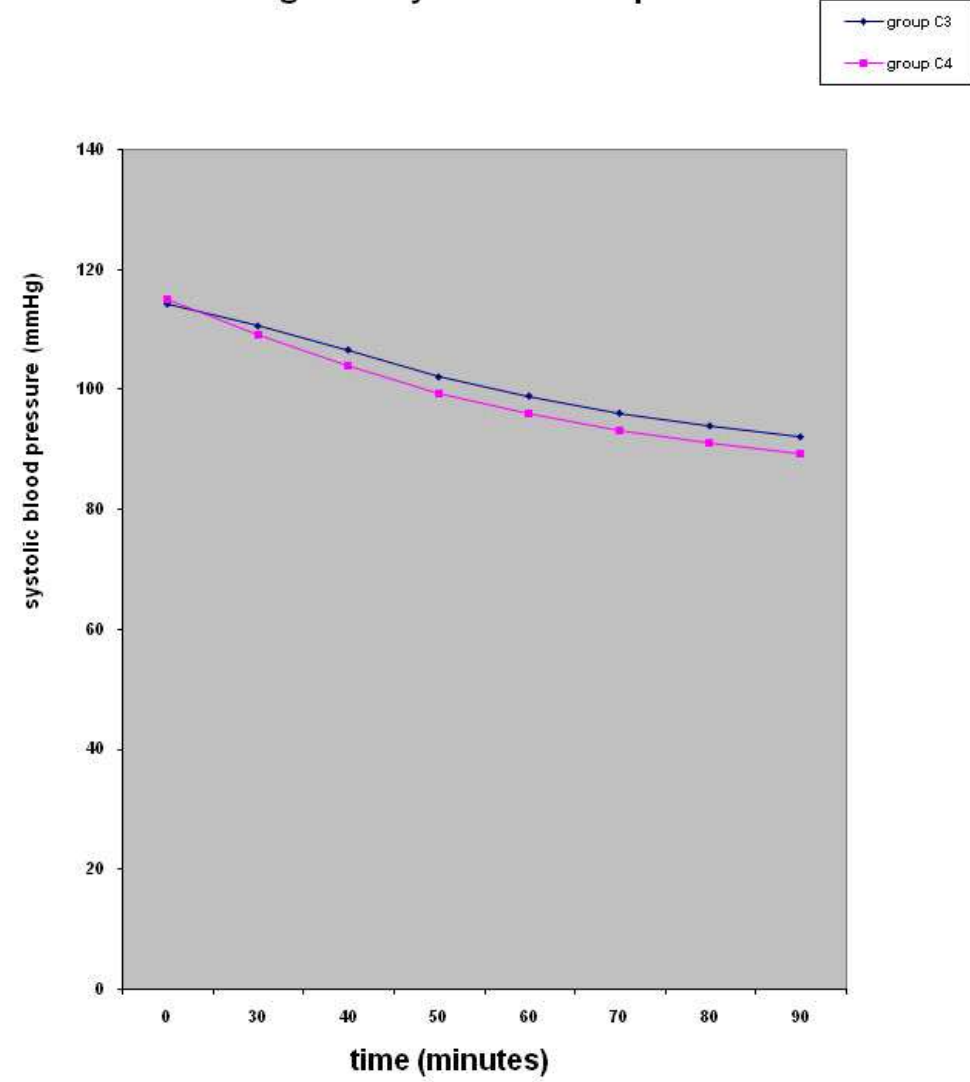
Table No. 3A : RESPONSE TO INTUBATION

PULSE RATE/ MINUTE

\begin{tabular}{|c|c|c|c|}
\hline TIME/ MINUTE & GROUP $_{3}$ Mean \pm SD & GROUP $_{4}$ Mean \pm SD & P VALUE \\
\hline 1. & $115.26 \pm 3.30$ & $103.33 \pm 2.69$ & $\mathrm{P}<0.001$ \\
\hline 3. & $125.26 \pm 3.91$ & $114.80 \pm 2.44$ & $\mathrm{P}<0.001$ \\
\hline 5 & $103.80 \pm 3.37$ & $92.26 \pm 2.76$ & $\mathrm{P}<0.001$ \\
\hline
\end{tabular}

Table No. 3B: SYSTOLIC BLOOD PRESSURE ( $\mathrm{mm} \mathrm{Hg}$ )

\begin{tabular}{|c|c|c|c|}
\hline $\begin{array}{c}\text { TIME/ } \\
\text { MINUTE }\end{array}$ & GROUP C $_{3 \text { Mean } \pm \text { SD }}$ & GROUP C $_{\text {M Mean } \pm \text { SD }}$ & P VALUE \\
\hline 1. & $108.93 \pm 3.13$ & $101.26 \pm 2.69$ & $\mathrm{P}<0.001$ \\
\hline 3. & $121.06 \pm 3.51$ & $114.8 .8 \pm 1.89$ & $\mathrm{P}<0.001$ \\
\hline 5 & $101.7 \pm 3.79$ & $91.46 \pm 1.47$ & $\mathrm{P}<0.001$ \\
\hline
\end{tabular}

